www.jmscr.igmpublication.org

Impact Factor 3.79

Index Copernicus Value: 5.88 ISSN (e)-2347-176x ISSN (p) 2455-0450 crossref DOI: _http://dx.doi.org/10.18535/jmscr/v4i02.50

\title{
To Study Clinical Profile of Tuberculosis in Patients of Diabetes Mellitus
}

(Original Article)

Authors

\author{
Dr Ritu Gupta ${ }^{1}$, Dr Sandeep Singh ${ }^{2}$, Dr Mahesh Vijay Bodkhe ${ }^{3}$ \\ ${ }^{1}$ Associate Prof. Netaji Subhash Chandra Bose Medical College Jabalpur, \\ ${ }^{2}$ Assistant Prof. Netaji Subhash Chandra Bose Medical College Jabalpur, \\ ${ }^{3} \mathrm{PG}$ third year, Netaji Subhash Chandra Bose Medical College Jabalpur,
}

Dept Of Medicine, Netaji Subhash Chandra Bose Medical College, Jabalpur, Madhya Pradesh, India

Corresponding Author

\section{Dr Ritu Gupta}

W/O Dr Amit Gupta, 207, Ravindra Nagar, Adhartal, Jabalpur (M.P), Pin: 482004

Email: dr.ritugupta76@yahoo.in Mob.no.9425861502

\begin{abstract}
Diabetes mellitus is an independent risk factor for lower respiratory tract infections. Patients with diabetes are at greater risk of contracting tuberculosis, and diabetes can worsen the course of tuberculosis. Hyperglycemia appears to be a contributory factor to the development of pulmonary tuberculosis in diabetic patients. Complications related to uncontrolled blood sugar level are high in patients with tuberculosis. Also tuberculosis affects the effective control of blood sugar in diabetic patients requiring increase need of OHA and insulin. So both diseases have add on effect on others, pathogenicity control and management.

Results: Total 150 cases of diabetes mellitus taken.Maximum patients belong's to age group $>60$ yrs in non-tuberculosis \& 51-60 years in tuberculosis group; Male are More affected than Female. Most Common symptom was chest pain (29.62\%) in patients of diabetes without tuberculosis may be due to older age group whereas anorexia (100\%) was most common symptom in patients of tuberculosis with diabetes. When we compare clinical profile of diabetic patients it was found that pulse rate is high, systolic and diastolic blood pressure was found to be significantly lower, mean PPBS (290.24 mg\%) higher, total cholesterol lower, weight \& BMI significantly lower in tubercular group. In clinical profile of diabetes with tuberculosis patients among all the studied parameters total cholesterol, LDLc and weight was found to be significantly lower in pulmonary as compared with extra pulmonary tuberculosis. Complications like retinopathy, neuropathy, nephropathy and other macrovascular complications are more in tubercular group but difference in retinopathy statistically significant .Chest radiograph revealed that $11.76 \%$ of patients had unilateral \& $70.58 \%$ had bilateral lesions in which predominant lesion in middle \& lower zone i.e $41.17 \%$. Cavity noted in $17.60 \%$.

Keywords: OHA: Oral hypoglycaemic agents, HIV: Human immunodeficiency virus, CSF: Cerebrospinal fluid, PPBS: Post prandial blood sugar, LDLc: Low density lipoprotein's.
\end{abstract}




\section{Introduction}

There exists evidence that DM is an independent risk factor for lower respiratory tract infections. TB occurs with an increased frequency in diabetics and causes significantly higher mortality, increased reactivations of TB lesions have also been recorded in diabetics. TB also appears to aggravate DM with patients requiring increase in dosage regimen of treatment for control $^{(1)}$. Tuberculosis is five to six times more common among diabetics than among nondiabetics and causes greater morbidity, according to reports. The effective control of each affects the control of the other ${ }^{(2)}$.

So in patients with diabetes, we need to think about TB and screen them, and in patients with $\mathrm{TB}$, we need to think about diabetes. If we do not seriously think about the link between TB and diabetes, it may begin to derail some of the good advances made in TB control, especially in countries like China and India. The increasing incidence of diabetes, especially in low- and middle-income countries, is threatening to have a negative impact on TB control, and vice versa ${ }^{(3)}$. In addition to the above, TB and its treatment may also worsen the glycaemic control in a subject with diabetes, it may also facilitate the progression of complications related to diabetes especially neuropathy. Several studies indicate that diabetes is associated with increased death rate in patient with TB. These studies showed that the risk of death was six times higher in TB patients with DM ${ }^{(5)}$. Plasma levels of IL-1 and TNF alpha are also raised in severe illness which can stimulate the anti-insulin hormones ${ }^{(4)}$. In our study clinical profile of tuberculosis in patients of diabetes mellitus was done \& get percentage of tuberculosis in patients of diabetes mellitus and effect of tuberculosis on diabetics.

\section{Material and Method}

Present study was conducted in NSCB Medical college Jabalpur during period of October 2014 to September 2015 in patients of diabetes (Type I $\&$ II ).Patients were interviewed with a structured questionnaire which sought information on the socio-demographic characteristics of the patients, (age, sex, occupation, marital status) duration of symptoms, their presenting complaints and prior history of tuberculosis. Relevant investigations like X -ray chest, sputum smear result, HIV status, and Tuberculin test, fasting and postprandial blood sugar, ascitis, pleural , CSF fluid examination done. Investigations to diagnose complications like 1) Nephropathy: Blood urea, serum creatinine, USG abdomen, urine routine \& microscopy, $24 \mathrm{hr}$. urinary protein.2)Diabetic retinopathy: Fundus examination 3)Any evidence of IHD : ECG, 2D echo. 4) Neuropathy: Clinical examination done. Appropriate statistical tests such as Chi-square test, Independent t-test \& non parametric tests were used wherever applicable.

Patients with HIV, Connective tissue disorder, on chemotherapy, other immunocompromised states, old treated cases of tuberculosis, patients not willing to be part of the study are excluded.

\section{Results}

Total 150 cases of diabetes mellitus taken. Maximum patients belongs to age group $>60 \mathrm{yrs}$ in non tuberculosis \& 51-60 years in tuberculosis group.( Table No.1); Male are More affected than Female i.e. Male: Female ratio $=1.6: 1$ (Total), Male: Female ratio $=1.49: 1$ (Non tubercular group), Male: Female ratio $=2.28: 1$ (Tubercular group) (table no 2); Most common symptom was chest pain(29.62\%) in patients of diabetes without tuberculosis were as anorexia(100\%) was most common symptom in patients of tuberculosis with diabetes. When we compare clinical profile of diabetic patients it was found that pulse rate is high, systolic and diastolic blood pressure was found to be significantly lower, mean PPBS (290.24 mg\%) higher, total cholesterol lower, weight \& BMI significantly lower in tubercular group.(Table no.3). In clinical profile of diabetes with tuberculosis patients among all the studied parameters total cholesterol, LDLc and weight was found to be significantly lower in pulmonary as compared with extra pulmonary tuberculosis. 


\section{JMSCR Vol||4||Issue||02||Page 9403-9411||February}

(Table no.4) .Complications like retinopathy , neuropathy ,nephropathy and other macrovascular complications are more in tubercular group but difference in retinopathy statistically significant $(p<0.05)($ Table no.5) .Examination of chest radiograph revealed that $11.76 \%$ of patients had unilateral \& $70.58 \%$ had bilateral lesions in which predominant lesion in middle \& lower zone i.e $41.17 \%$. Cavity noted in $17.60 \%$.(Table No.6)

Table No.1 Clinical Profile Of Diabetics Patients

\begin{tabular}{|c|c|c|}
\hline \multirow{2}{*}{ Age } & $\begin{array}{c}\text { Non-Tubercular } \\
(\mathrm{n}=127)\end{array}$ & $\begin{array}{c}\text { Tubercular } \\
(\mathrm{n}=23)\end{array}$ \\
\cline { 2 - 3 } & $\%$ & $\%$ \\
\hline $15-30 \mathrm{yrs}$ & $4.70 \%$ & $4.30 \%$ \\
\hline $31-40 \mathrm{yrs}$ & $7.10 \%$ & $21.80 \%$ \\
\hline $41-50 \mathrm{yrs}$ & $24.40 \%$ & $17.30 \%$ \\
\hline $51-60 \mathrm{yrs}$ & $26.00 \%$ & $34.80 \%$ \\
\hline$>60 \mathrm{yrs}$ & $37.80 \%$ & $21.80 \%$ \\
\hline TOTAL & $100 \%$ & $100 \%$ \\
\hline
\end{tabular}

TABLE No. 2 SeX WiSe Distribution

\begin{tabular}{|c|c|c|c|c|}
\hline \multirow{3}{*}{ sex } & \multicolumn{4}{|c|}{ Total Patients } \\
\hline & \multicolumn{2}{|c|}{ Non Tuberculosis } & \multicolumn{2}{|c|}{ Tuberculosis } \\
\hline & $\mathrm{N}$ & $\%$ & $\mathrm{~N}$ & $\%$ \\
\hline Male & 76 & $59.84 \%$ & 16 & $69.56 \%$ \\
\hline Female & 51 & $40.16 \%$ & 7 & $30.44 \%$ \\
\hline TOTAL & 127 & $100 \%$ & 23 & $100 \%$ \\
\hline
\end{tabular}


TABLE No.3

\begin{tabular}{|c|c|c|c|c|c|c|c|}
\hline \multirow[b]{2}{*}{ Variable } & \multirow[b]{2}{*}{ Variable } & \multicolumn{2}{|c|}{ Non tuberculosis } & \multicolumn{2}{|c|}{ Tuberculosis } & \multirow[b]{2}{*}{$\mathrm{t}$ test } & \multirow[b]{2}{*}{$\mathrm{p}$ value } \\
\hline & & Mean & $\begin{array}{l}\text { Std. } \\
\text { Dev. }\end{array}$ & Mean & $\begin{array}{l}\text { Std. } \\
\text { Dev. }\end{array}$ & & \\
\hline 1 & PULSE & 86.49 & 12.08 & 94.34 & 12.33 & 2.86 & 0.005 \\
\hline 2 & SBP & 137.84 & 31.22 & 110.08 & 17.69 & 4.14 & 0.0001 \\
\hline 3 & DBP & 84.28 & 14.43 & 71.91 & 10.15 & 3.93 & 0.0001 \\
\hline 4 & $\mathrm{RR}$ & 20.7 & 9.95 & 24.73 & 12.14 & 1.73 & 0.182 \\
\hline 5 & $\mathrm{Hb}$ & 11.67 & 2.26 & 10.02 & 2.25 & 0.51 & 0.61 \\
\hline 6 & TLC & 8954.16 & 4055.11 & 8073.91 & 2543.6 & 1 & 0.32 \\
\hline 7 & FBS & 198.1 & 106.06 & 217.69 & 105.91 & 0.82 & 0.42 \\
\hline 8 & PPBS & 290.25 & 124.86 & 347.91 & 58.9 & 2.09 & 0.04 \\
\hline 9 & TOTAL CHO & 163.72 & 45.92 & 142.65 & 39.14 & 2.07 & 0.04 \\
\hline 10 & HDLC & 35.59 & 13.82 & 34.78 & 13.2 & 0.335 & 0.74 \\
\hline 11 & LDLC & 95.4 & 41.76 & 92.04 & 40.44 & 0.65 & 0.52 \\
\hline 12 & TG & 194.86 & 501.61 & 130.91 & 50.94 & 0.6 & 0.55 \\
\hline 13 & VLDLC & 34.25 & 26.09 & 26.72 & 11.77 & 1 & 0.32 \\
\hline 14 & $\begin{array}{l}\text { BILIRUBIN } \\
(\mathrm{T})\end{array}$ & 1.13 & 4.04 & 0.75 & 0.52 & 0.45 & 0.6 \\
\hline 15 & SGPT & 36.89 & 42.01 & 38.3 & 51.65 & 0.14 & 0.89 \\
\hline 16 & SGOT & 48.63 & 46.91 & 34.78 & 14.34 & 1.4 & 0.16 \\
\hline 17 & UREA & 53.54 & 42.5 & 37.39 & 31.17 & 1.74 & 0.08 \\
\hline 18 & CREATININE & 1.62 & 1.82 & 1.15 & 0.97 & 1.2 & 0.23 \\
\hline 19 & WT & 63.65 & 10.23 & 49.39 & 4.73 & 6.54 & $<0.0001$ \\
\hline 20 & HT & 160.96 & 8.32 & 159.69 & 8.42 & 0.67 & 0.84 \\
\hline 21 & BMI & 24.47 & 2.82 & 19.41 & 1.89 & 8.25 & $<0.0001$ \\
\hline
\end{tabular}




\section{JMSCR Vol||4||Issue||02||Page 9403-9411||February}

Table No.4 Clinical Profile Of Diabetes With Tuberculosis Patients

\begin{tabular}{|l|l|l|l|l|l|l|l|}
\hline \multirow{2}{*}{ S.No. } & \multirow{2}{*}{ Variable } & Pulmonary & Extra Pulmonary & & \\
\cline { 3 - 8 } & & Mean & $\begin{array}{l}\text { Std. } \\
\text { Dev. }\end{array}$ & Mean & $\begin{array}{l}\text { Std. } \\
\text { Dev. }\end{array}$ & t test & p value \\
\hline 1 & PULSE & 95.29 & 12.84 & 91.66 & 11.41 & 0.61 & 0.55 \\
\hline 2 & SBP & 107.76 & 17.91 & 116.66 & 16.76 & 1.06 & 0.3 \\
\hline 3 & DBP & 71.17 & 10.63 & 74 & 9.2 & 0.58 & 0.57 \\
\hline 4 & RR & 22.64 & 3.88 & 30.66 & 23.3 & 1.42 & 0.17 \\
\hline 5 & Hb & 9.96 & 2.4 & 10.18 & 2.01 & 0.2 & 0.84 \\
\hline 6 & TLC & 8117.64 & 2372.03 & 7950 & 3230.94 & 0.14 & 0.89 \\
\hline 7 & FBS & 231.17 & 114.12 & 179.5 & 72.87 & 1.03 & 0.31 \\
\hline 8 & PPBS & 353.17 & 134.02 & 256.33 & 85.48 & 1.64 & 0.12 \\
\hline 9 & TOTAL CHO & 131.17 & 29.94 & 175.16 & 46.43 & 2.68 & 0.01 \\
\hline 10 & HDLC & 33.05 & 14.74 & 39.66 & 5.68 & 1.06 & 0.3 \\
\hline 11 & LDLC & 81.11 & 31.11 & 123 & 50.42 & 0.52 & 0.025 \\
\hline 12 & TG & 120 & 45.7 & 161.83 & 56.4 & 0.55 & 0.08 \\
\hline 13 & VLDLC & 24.77 & 11.6 & 32.26 & 11.34 & 0.32 & 0.19 \\
\hline 14 & BILIRUBIN (T) & 0.69 & 0.34 & 0.91 & 0.88 & 0.6 & 0.4 \\
\hline 15 & SGPT & 32.11 & 37.53 & 55.83 & 82.04 & 0.97 & 0.34 \\
\hline 16 & SGOT & 33.58 & 12.69 & 38.16 & 19.27 & 0.66 & 0.51 \\
\hline 17 & UREA & 39.17 & 35.01 & 32.33 & 17.64 & 0.45 & 0.65 \\
\hline 18 & CREATININE & 1.12 & 1.04 & 1.22 & 0.81 & 0.16 & 0.85 \\
\hline 19 & WT & 48.17 & 4.55 & 52.83 & 3.6 & 2.25 & 0.035 \\
\hline 20 & HT & 157.94 & 8.74 & 164.66 & 5.2 & 1.76 & 0.09 \\
\hline 21 & BMI & 19.38 & 1.97 & 19.52 & 1.8 & 0.16 & 0.87 \\
\hline & & & & & & & \\
\hline & & & & & & \\
\hline
\end{tabular}

Table No.5 Complications

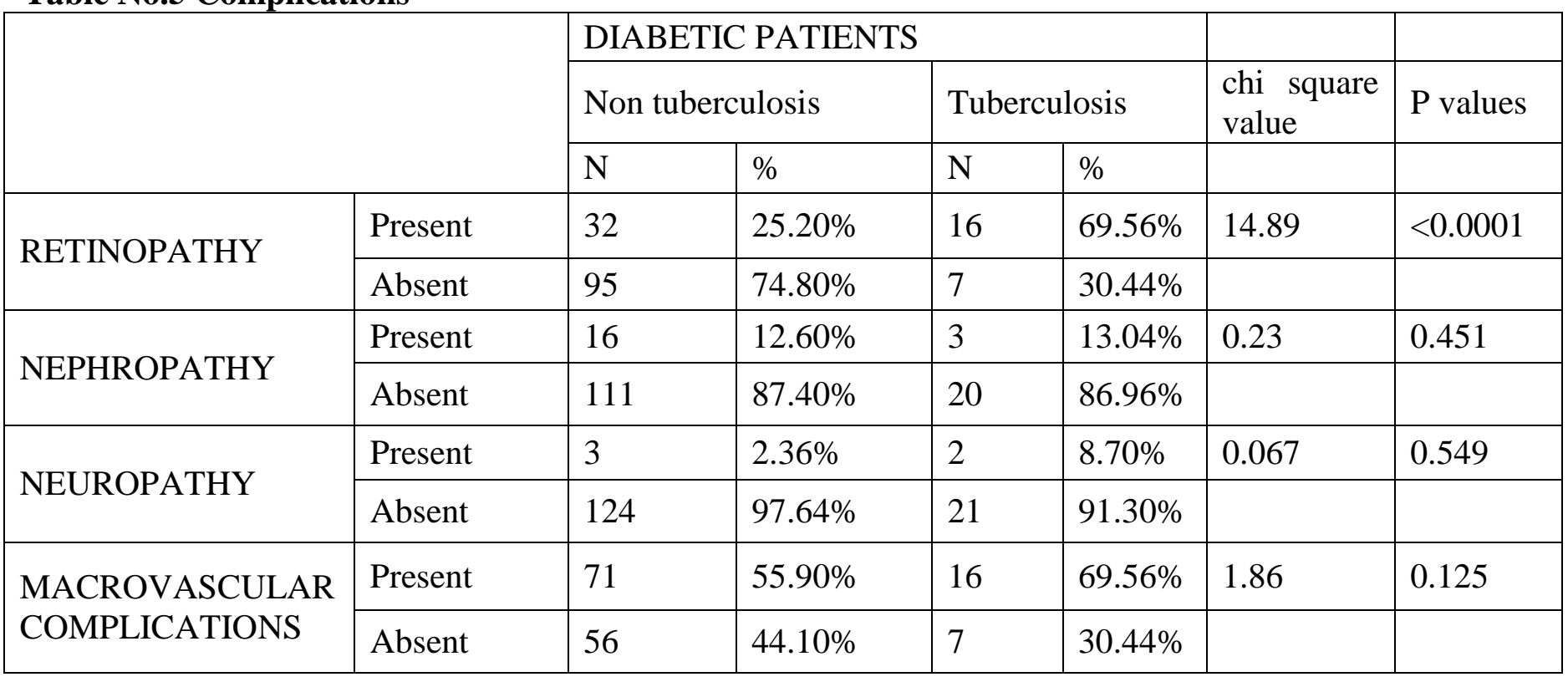


Table No.6

\begin{tabular}{|c|c|c|c|c|c|}
\hline \multirow{2}{*}{} & \multicolumn{4}{|c|}{ X-RAY PRESENTATION } \\
\cline { 3 - 6 } & \multicolumn{2}{|c|}{ Pulmonary } & \multicolumn{2}{c|}{ Extra-pulmonary } \\
\cline { 3 - 6 } & & Count & N \% & Count & N \% \\
\hline \multirow{2}{*}{ Xraychest } & UL & 2 & $11.66 \%$ & 0 & $0.00 \%$ \\
\hline \multirow{2}{*}{} & B/L UL & 5 & $29.41 \%$ & 0 & $0.00 \%$ \\
\hline & MID \& LL & 7 & $41.17 \%$ & 0 & $0.00 \%$ \\
\hline & PE & 2 & $11.76 \%$ & 4 & $66.67 \%$ \\
\hline & WNL & 0 & $0.00 \%$ & 2 & $33.33 \%$ \\
\hline & MILIARY & 1 & $6.00 \%$ & 0 & $0.00 \%$ \\
\hline & TOTAL & 17 & $100.00 \%$ & 6 & $100.00 \%$ \\
\hline
\end{tabular}

\section{Discussion}

The present study is hospital based cross-sectional study, to study clinical profile of tuberculosis in patients of diabetes mellitus with gathered data, the peak incidence of tuberculosis in diabetic patients in the age groups of $51-60$ in tubercular $(34.80 \%)$ and more than 60 years in non tubercular group (37.80\%), this might be a case selection bias and not necessarily has any inference on the severity of the illness. Desmukhet.al reported that higher incidence of tuberculosis diabetics in people over the age of 40 yrs ${ }^{(6)}$.

Total 150 diabetes mellitus cases taken. Out of which $92(61.33 \%)$ were males, 58(38.66\%) were females, male to female ratio was 1.6:1.In a study by Deshmukh et.al ${ }^{(6)}$. All the above studies showed an increased incidence of the disease in males as compared to females and our study also noted the same.

Patients presenting with tuberculosis the predominant symptoms noted were anorexia (100\%), fever (86.95\%), cough $(73.91 \%)$, and loss of weight $(73.91 \%)$.In a study done in Ethiopian diabetic patients with tuberculosis, most common symptoms of tuberculosis were fever $(80.5 \%)$, sweating $(80.4 \%)$ and cough $(70.5 \%){ }^{(7)}$.
Tachycardia common in tubercular group. Similar findings were found by Thomson Campbell in 1901 in patients of pulmonary tuberculosis ${ }^{(8)}$.

In our study systolic and diastolic blood pressure was found to be significantly lower in tubercular group. In a study done by Mugusi $\mathrm{F}$,Swai AB in Tanzania findings are consistent with reported observations in Zulu patients with pulmonary tuberculosis, and suggest that impaired adrenal function may contribute to morbidity and even mortality among patients with tuberculosis in Africa. Adrenal hypofunction should be considered in any tuberculosis patient with hypotension and poor response to chemotherapy (9).

$43.33 \%$ of the patients in our study were found to be anemic. Of these $22 \%$ had mild anemia, $23 \%$ had moderate anemia and $6 \%$ had severe anemia similar to study done in Jammu region by Pavan Malhotra et.al ${ }^{(10)}$. The discrepancy between the percentages of anemic patients may be due to various factors: the patient selection process, demographic characteristics, dietary habits.

The total white cell count in our study was 8954.16 in non tubercular group and 8073.91 in tubercular group ${ }^{(11)}$. Knelle et.al has proved that leukocyte picture is of no help in diagnosis of tuberculosis and our study also shows the same. ${ }^{(11)}$ 
Mean FBS was $198.10 \mathrm{mg} \%$ in non tubercular and $217.69 \mathrm{mg} \%$ in tubercular group \& mean PPBS was $290.25 \mathrm{mg} \%$ in non tubercular and 347.91 $\mathrm{mg} \%$ in tubercular group. This showed that in most of the cases blood sugar was poorly controlled in patients with tuberculosis. In a study done by Sachdeva AK et.al ${ }^{(12)}$, Deshmukh PA et.al also had made a similar observation ${ }^{(6)}$. The finding in this study is consistent with the proposal that there is correlation between infection and plasma glucose levels ${ }^{(13)}$.

Total cholesterol level is significantly lower in tubercular group. $(\mathrm{p}<0.05) \quad$ Accumulating literatures have described the difference in lipid profiles between TB and health controls, showing lower levels of total cholesterol, LDL, and highdensity lipoprotein level in TB cases Some authors speculated that it might be the result of increased lipid metabolism during inflammatory or infection status for immune response ${ }^{(14)}$.

There was no difference in liver function test between tubercular and non tubercular group.

Blood urea level is more in non-tubercular group. Hyperglycemia, increased blood pressure levels, and genetic predisposition are the main risk factors for the development of diabetic nephropathy. Elevated serum lipids, smoking habits, and the amount and origin of dietary protein also seem to play a role as risk factors. ${ }^{(15)}$

In our study mean weight was found to be 63.65 $\mathrm{kg}$ in non tubercular and $49.39 \mathrm{~kg}$ in tubercular group and the difference was found to be statistically significant. Similarly BMI was found to be 24.47 in non tubercular and 19.41 in tubercular group and the difference was found to be statistically significant. A study by $S$ Govindarajan et.al have reported similar results (16)

In clinical profile of diabetes with tuberculosis patients among all the studied parameters total cholesterol, LDLc and weight was found to be significantly lower in pulmonary as compared with extra pulmonary tuberculosis.

In our study among the studied complications retinopathy was found to be statistically significant $(p<0.05)$ ie. more in patients with tuberculosis. In study done by Neeti Gupta, Rohit Gupta et al explained that Corticosteroids have shown to inhibit the expression of both VEGF and VEGF gene and have anti-inflammatory properties which explains the rationale to use steroids for diabetic macular oedema \& steroid levels are lower in patients with tuberculosis. ${ }^{(17)}$ Also other complications like nephropathy (13.04\%), neuropathy $(8.69 \%) \&$ macrovascular complication $(69.56 \%$ ) were found to be more in patients of tuberculosis with diabetes but the difference was not found to be statistically significant.

The examination of chest radiograph revealed that $11.76 \%$ of the patients had unilateral lesions and $70.58 \%$ of the patients had bilateral lesions. In both these group, predominant lesions were noted in the mid \& lower zone. In our study also, cavity and bilateral mid \& lower lobe involvement ismore compared to other lesions. Multiple cavitations were seen. Our study correlates with most of the above radiological studies in regards to the side of lesion, site of lesion, extent of lesion as well as nature of radiological patterns consisted with study done by Perez Guzman et.al, it was reported that more tuberculous diabetics develop multiple cavities and also cavitations were more in lower lung field. ${ }^{(18)}$ In our study $47.05 \%$ of were sputum positive for acid fast bacilli. Also cavitation were noted in $17.60 \%$ patients.

In our study 23 out of $150(15.33 \%)$ diabetic patients were found to be suffering from tuberculosis. A systematic review and a metaanalysis of 13 observational studies ( $\mathrm{n}=$ $1,786,212$ participants) with 17,698 TB cases, suggests that DM increases the risk of active TB. Random effects meta-analysis of cohort studies showed that DM was associated with an increased risk of $\mathrm{TB}$ (relative risk $=3.11,95 \%$ CI 2.27 4.26). TB prevalence in this population is high, ranging from $1.7 \%$ to $36 \%{ }^{(19)}$ 


\section{Conclusion}

So based of above study hyperglycemia appears to be a contributory factor to the development of pulmonary tuberculosis in diabetic patients. Multiple cavities and multiple lobe involvement are more common in tubercular diabetic patients. Complications related to uncontrol blood sugar level are high in patients with tuberculosis. So control of blood sugar is important in diabetic patients. Also tuberculosis affect the effective control of blood sugar in diabetic patients requiring increase need of OHA and insulin. So both disease have an add on effect on others, pathogenically control and management.

So early diagnosis and treatment of tuberculosis in diabetic patients can prevent further deterioration of the disease and vice-versa, as already given WHO guidelines Sept. 2011. ${ }^{(20)}$

\section{Acknowledgement}

Dr. Shirish Tiwari Medical officer, RNTCP. Netaji Subhash Chandra Bose Medical College Jabalpur.

\section{Bibliography}

1. SoundararajanRaghuraman, Kavita $P$ Vasudevan, S Govindarajan, ${ }^{1}$ Palanivel Chinnakali, and Krishna Chandra Panigrahi Prevalence of Diabetes Mellitus among Tuberculosis Patients in Urban Puducherry.. (N Am j med sci 2014 jan 6 ; 30-4. doi:10.4103/1947-2714.125863)

2. Study on prevalence of diabetes mellitus in tuberculosis [Indian J Tuberc. 2014] PubMed - NCBI \& http://www.who.int/bulletin/volumes/89/5/ 10-085738/en]

3. Dr. Murugnathan ,DR. Vijay vishwanathan Double Burden of Tuberculosis and Diabetes in India section 5 API : Chapter 32 The by Dr. Murugnathan ,DR. Vijay vishwanathan.

4. Gonzalen et. al High glucose concentration induced TNF- alfa production through the down regulation of $\mathrm{CD}$-33in primary human monocytes. By BMC immunology 2012 13:19

5. Singla R, Khan N, Al-Sharif N, Al-Sayegh $\mathrm{O}$, Shaikh M, Osman M. Influence of diabetes on manifestations and treatment outcome of pulmonary TB patients. Int $\mathbf{J}$ Tuberc Lung Dis 2006; 10: 74-9.

6. Deshmukh PA, Shaw T. Pulmonary tuberculosis and diabetes mellitus. Ind $\mathrm{J}$ Tub 1984;31:114

7. Feleke Y, Abdulkadir J, Aderaye G. Prevalence and clinical features of tuberculosis in Ethiopian diabetic patients. East Afr Med J 1999;76(7):361-64.

8. Thompson Campbell The Pulse Rate in Pulmonary Tuberculosis BY Med J. 1901 Jun 1; 1(2109): 1334-1335.

9. MugusiF ,Swai AB, Turner SJ, Alberti KG, McLarty DG. Trans R Soc Hypoadrenalism in patients with pulmonary tuberculosis in Tanzania: anundiagnosed Trop Med Hyg. 1990 NovDec;84(6):84951.

10. Malhotra P. Prevalence of tuberculosis in kishtwar Tehsil of Jammu region. J Indian Med Assoc 1996;94:334-337.

11. Gordonleitch A., Anthony Seaton, Douglas Seaton, Gordonleitch A, editors. Crofton and Douglas's respiratory diseases. 5th edition. 2 vol: vol 1. Oxford: Blackwell Science; 2000.p.515-521.

12. Sachdeva AK, Arora RC, Misra DN. Clinicoradiological study of pulmonary tuberculosis in diabetics. $\mathrm{J}$ Assoc Physicians India 1984;32:30.

13. Oluboyo PO, Erasmus RT. The significance of glucose intolerance in pulmonary tuberculosis. Tubercle 1990;71(2):135-38.

14. Yung-Hsiang Lin, Chia-Pei Chen, PaoYing Chen, Jui-Chu Huang, Cheng Ho, Hsu-HueiWeng, Ying-Huang Tsai and Yun-Shing Peng Screening for pulmonary tuberculosis in type 2 diabetes elderly: a cross-sectional study in a community 
hospital( TAIWAN). (BMC public health. 2015 jan 8; 15:3.doi 10.1186/1471-245815-3.)

15. Diabetic Nephropathy: Diagnosis, Prevention, and Treatment. Diabetes Carecare.diabetesjournals.ORG DOI: 10.2337/diacare.28.1.164 Diabetes Care January 2005 vol. 28 no. 1 164-176

16. SoundararajanRaghuraman, Kavita P Vasudevan, $S$ Govindarajan, ${ }^{1}$ PalanivelChinnakali, and Krishna Chandra Panigrahi Prevalence of Diabetes Mellitus among Tuberculosis Patients in Urban Puducherry.. ( $\mathrm{N} \mathrm{Am} \mathrm{j}$ med sci 2014 jan 6 ; 30-4. doi:10.4103/1947-2714.125863)

17. Neeti Gupta, Rohit Gupta Diabetic Retinopathy-An Update Department of Ophthalmology and Medicine,

Himalayan Institute of Medical Science, Dehradun, Uttarakhand, India JIMSA Jan. - Mar. 2015 Vol. 28 No. 1

18. Pérez-Guzmán $\mathrm{C}$, Vargas $\mathrm{M}$, Torres-Cruz A, Pérez-Padilla J, Furuya M, VillarrealVelarde H. Diabetes modifies the male : female ratio in pulmonary tuberculosis. Int J Tuberc Lung Dis 2003; 7: 354-8.

19. Dr. NavneetWadhwa, MD (Pharmacology), Tuberculosis and Diabetes - The Converging Epidemic Mumbai, India.(Journal of Clinical and Preventive Cardiology, January 2015 ).

20. www.who.int./tb/publications/sept 2011. 